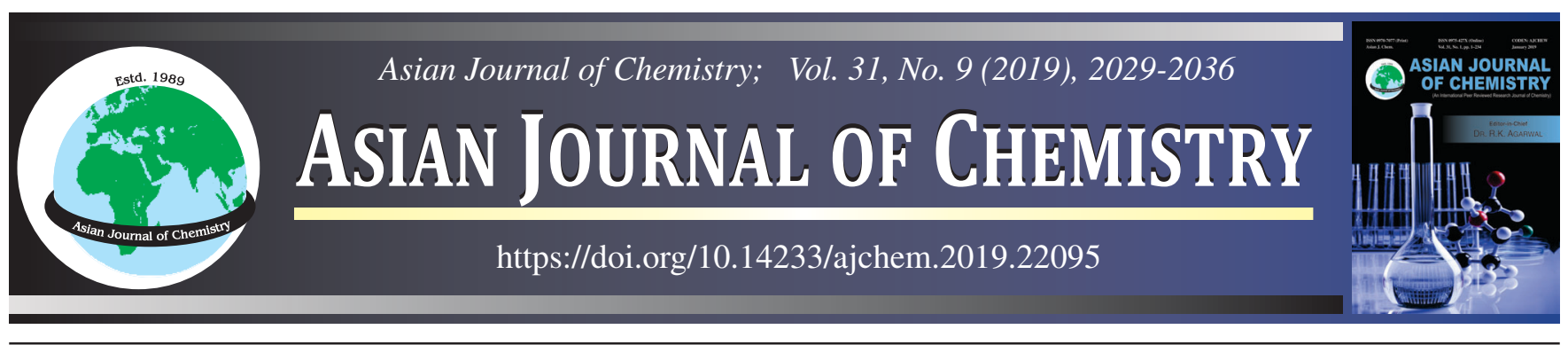

\title{
Physico-Chemical Studies of Chitosan Derivatives and Optimization of Reaction Conditions using RSM Design
}

\author{
Vandana Suryavanshi ${ }^{1}$, Alekha Kumar $\operatorname{SutaR}^{2}$ and Tungabidya Maharana ${ }^{1, *}$
}

${ }^{1}$ Department of Chemistry, National Institute of Technology, Raipur-492010, India

${ }^{2}$ Catalysis Research Lab, Department of Chemistry, Ravenshaw University, Cuttack-753003, India

*Corresponding author: Fax: +91 771 2254600; Tel.: +91 771 2254200; E-mail: tmaharana.chy@ nitrr.ac.in

Received: 24 March 2019;

Accepted: 23 April 2019;

Published online: 31 July 2019;

AJC-19493

In this work, the chitosan flake was converted to carboxymethyl chitosan (CMCS) by carboxymethylation process using monochloroacetic
acid in alkaline condition. The structure of carboxymethyl chitosan was confirmed by NMR, FT-IR, XRD, TGA and SEM techniques.
The average molecular weight of carboxymethyl chitosan was obtained by viscometry method. The carboxymethylation reaction of
chitosan was optimized for the reaction time, reaction temperature, amount of chitosan, amount of monochloroacetic acid. Response
surface methodology (RSM) was used to analyze degree of substitution, degree of acetylation and yield with respect to reaction conditions.
At the optimization reaction condition the degree of substitution, degree of acetylation (\%) and yield $(\%)$ values are $0.56,33.99$ and 78.2 ,
respectively. |

Keywords: Chitosan, Carboxymethylation, Response surface methodology, Degree of substitution, Degree of acetylation.

\section{INTRODUCTION}

Chitosan, a biodegradable heteropolysaccharide of glucosamine and $N$-acetyl glucosamine units linked by $1,4-\beta$-glucosidic bonds is produced by deacetylation of chitin. Chitin (poly$(\beta$ - $(1 \rightarrow 4)-N$-acetyl-D-glucosamine), is a biopolysaccharide found in nature, second most abundant in the world, originated from the cell wall of fungi and also found from crab, fish, shrimp shells as well as exoskeletons of insects and crustacean, fungal cell wall, etc. [1]. Further, technology of controlled drug delivery system using biodegradable and biocompatible polymers is one of the most promising field of medical science [2,3]. Chitosan exhibits significant biological (biocompatibility, biodegradability, nontoxicity, bioactivity, non-immunogenic and non-carcinogenic) and chemical properties (polycationic, hydrogel, reactive functional groups such as hydroxyl (-OH) and amino $\left(-\mathrm{NH}_{2}\right)$ groups. Chitosan has a strong positive electrical charge, which strongly attracts and bonds to negatively charged molecules [4]. Chitosan have been widely utilized in nutrition, cosmetics, several pharmaceutical and biomedical applications, textile finishes, membranes, hollow fibers, drug delivery system $[2,5]$. Therefore, chitosan has prospective potential applications in many fields such as tissue engineering, biomedicine, waste water treatment, functional membrane and flocculation. Chitosan also finds its application in novel drug delivery as mucoadhesive, peptide and gene delivery, and oral enhancer have also been reported [5,6]. It is also used in cosmetics, agriculture and biomaterials and in particular, excellent activity as a wound healing accelerator combined with antibacterial capability and good tissue compatibility of chitosan made it become an excellent wound dressing materials. However, chitosan is soluble in only a few dilute acid solutions, so the poor solubility of unmodified chitosan in both water and organic solvents makes its utilization limited in the biomedical fields. Chitosan is a basic polysaccharide. In neutral or basic $\mathrm{pH}$, chitosan contains free amino groups and is insoluble in water, while in acidic $\mathrm{pH}$, chitosan is soluble in water due to protonation of free amino and $N$ acetyl groups. One of the reasons for the persistent behaviour of chitosan is due to its rigid crystalline structure. Therefore, recently, a modification of chitosan by chemical method is the most challenging field for polymer chemist to enhance the water solubility $[7,8]$.

Nowadays, chitosan derivatives should be the topic of indepth investigations. Among different types of modifications

This is an open access journal, and articles are distributed under the terms of the Attribution 4.0 International (CC BY 4.0) License. This license lets others distribute, remix, tweak, and build upon your work, even commercially, as long as they credit the author for the original creation. You must give appropriate credit, provide a link to the license, and indicate if changes were made. 
implemented to chitosan, introduction of carboxymethyl groups into chitosan is one of the important fields $[9,10]$. To the best of our knowledge, a few literature have been reported on proper study of carboxylmethyl chitosan having N,O-substituted carboxymethyl. Recently, our research group synthesized N, OSchiff base metal complexes which, resourcefully used for synthesis of polylactide [11,12].

Despite extensive utility of chitosan in many important biological and chemical transformations, still application of derivatives of chitosan (mainly carboxymethyl chitosan) largely remains unexplored. Because of the relative scarcity of proper reports on N,O-carboxymethyl chitosan, we embarked on a study of N,O-substituted carboxymethyl on chitosan. Herein, we reported the synthetic method for N,O-carboxymethylchitosan with a degree of acetylation (DA) and degree of substitution (DS).

\section{EXPERIMENTAL}

Biochemical reagent chitosan with deacetylation degree of $\geq 75 \%$ with medium molecular weight was purchased from Himedia Laboratories Pvt. Ltd., Mumbai, India. Monochloroacetic acid was purchased from S.D. Fine Chem Ltd., Mumbai, India. Sodium hydroxide, isopropyl alcohol and ethyl alcohol were obtained from Sigma-Aldrich and used without further purification.

Characterization: IR spectra were recorded using $\mathrm{KBr}$ pellet by Bruker Daltonics, Germany FTIR spectrophotometer over the frequency range from 4000 to $400 \mathrm{~cm}^{-1}$. Thermogravimetric analysis (TGA) and differential thermal analysis (DTA) of chitosan and their derivatives were carried out by using PerkinElmer Pyris-Diamond Thermal Analyzer at the temperature range of $25-750{ }^{\circ} \mathrm{C}$ under nitrogen atmosphere at a heating rate of $10^{\circ} \mathrm{C} \mathrm{min}^{-1}$. The NMR spectra were recorded on a Varian, USA, Mercury plus $300 \mathrm{MHz}$ Spectrometer using $\mathrm{CD}_{3} \mathrm{COOD} /$ $\mathrm{D}_{2} \mathrm{O}$ for chitosan and $\mathrm{D}_{2} \mathrm{O} / \mathrm{DCl}$ for chitosan derivative. Surface morphology of chitosan and their derivatives were carried out using a scanning electron microscope (SEM) EVO 10 Zeiss, Germany by coating the dried samples with gold-palladium alloy with a Sputter Coater before SEM analysis. The XRD studies of chitosan and its derivative were carried out by using PANanalytical 3KWX'Pert PW 3050/60, Netherlands. Data was collected in a continuous scan mode using a step size of $0.01^{\circ} 2 \theta[13]$.

The average molecular weight of chitosan derivatives can be determined by dissolving N,O-carboxymethyl chitosan samples in a solvent mixture $(0.3 \mathrm{M}$ acetic acid and $0.2 \mathrm{M}$ sodium acetate) and flowing the solution through an Ubbelhode capillary viscometer at room temperature. The average molecular weight of N,O-carboxymethyl-chitosan was determined [14] by Mark-Houwink-Sakurada's empirical equation .

$$
\eta=\mathrm{kM} \alpha
$$

where $\eta$ is the viscosity of solution; $M$ is the average molecular weight; $\mathrm{k}$ and $\alpha$ are the constants that depend on the solventpolymer system $(\mathrm{k}=0.076 \mathrm{~mL} / \mathrm{g}$ and $\alpha=0.76)$ [15].

The total degree of substitution (DS), relative number of carboxymethylated group in the chain of chitosan, was determined by using ELICO CM183EC-TDS conductivity analyzer
[16]. First, 0.1g of N,O-carboxymethyl chitosan were dissolved in $100 \mathrm{~mL}$ of $0.05 \mathrm{M} \mathrm{HCl}$ and then $0.1 \mathrm{M} \mathrm{NaOH}$ solution was added until the $\mathrm{pH}$ was changed to 2.0. Further, the prepared sample was titrated with $\mathrm{NaOH}(0.1 \mathrm{M})$ up to $\mathrm{pH} 12.0$.

The degree of acetylation can be calculated using eqns. 2 and 3:

$$
\begin{gathered}
\mathrm{DD}(\%)=\left(\frac{\mathrm{M} \times\left[\mathrm{V}_{\mathrm{s}}-\mathrm{V}_{\mathrm{z}}\right] \times[\mathrm{NaOH}]}{\mathrm{m}}\right) \times 100 \\
\operatorname{DA}(\%)=100-\% \mathrm{DD}
\end{gathered}
$$

where DD is the average degree of deacetylation; $\mathrm{M}$ is the molar mass of repetitive unit; $\mathrm{V}_{2}$ is the volume of base added to reach the second inflexion point; $\mathrm{V}_{3}$ is the volume of base added to reach the third inflexion point; $\mathrm{m}$ is the mass of sample (mg).

The degree of substitution (DS) of carboxymethyl chitosan was calculated as follows:

$$
\begin{gathered}
\mathrm{DS}=\frac{161 \times \mathrm{Q}}{\mathrm{m}_{\mathrm{cmc}}-58 \times \mathrm{Q}} \\
\mathrm{Q}=\mathrm{V}_{\mathrm{NaOH}} \times \mathrm{C}_{\mathrm{NaOH}} \\
\mathrm{V}_{\mathrm{NaOH}}=\mathrm{V}_{2}-\mathrm{V}_{1}
\end{gathered}
$$

where, $\mathrm{V}_{\mathrm{NaOH}}$ and $\mathrm{C}_{\mathrm{NaOH}}$ are the volume and molarity of aqueous $\mathrm{NaOH}$, respectively, and 161 and 58 are the molecular weights of chitosan skeleton unit (glucosamine) $\left(\mathrm{C}_{6} \mathrm{H}_{11} \mathrm{NO}_{4}\right)$ and carboxymethyl group [17,18]; $\mathrm{V}_{1}$ is the volume of $\mathrm{NaOH}$ added for the first inflexion point; $\mathrm{V}_{\mathrm{w}}$ is the volume of $\mathrm{NaOH}$ added for second inflexion point; and $\mathrm{m}$ is the weight of carboxymethylchitosan (mg).

Synthesis of N,O-carboxymethyl chitosan by chemical modification method: N,O-carboxymethyl chitosan were synthesized by the modified reported method $[8,19]$. Synthesis of N,O-carboxymethyl chitosan consists of two steps, alkalization followed by carboxymethylation. For alkalization, required amount of $\mathrm{NaOH}$ was dissolved in an isopropanol and water mixture, and subsequently chitosan was added with constant stirring for $1 \mathrm{~h}$. Then carboxymethylation reaction starts once isopropanol solution of monochloroacetic acid was added dropwise to the dispersion solution with continuously stirring at $400 \mathrm{rpm}$. The details of reaction temperature, reaction time, amount of chitosan and monochloroacetic acid are given in Table-1. The resulting solution was then filtered with Whatman filter paper No. 41 and then neutralized the sample by washing with $90 \%$ ethanol. Finally, the sample was dried in oven at 60 ${ }^{\circ} \mathrm{C}$ to obtain N,O-carboxymethyl chitosan powder.

\section{TABLE-1}

FACTORS VARIATION FOR CARBOXYMETHYL CHITOSAN

\begin{tabular}{cc}
\hline Factors & Range \\
\hline Reaction temperature $\left({ }^{\circ} \mathrm{C}\right)$ & $30-70$ \\
Reaction time $(\mathrm{h})$ & $2.0-10.0$ \\
Monochloroacetic acid $(\mathrm{g})$ & $1.0-4.0$ \\
Chitosan $(\mathrm{g})$ & $0.5-2.0$ \\
\hline
\end{tabular}

Experimental design: Response surface methodology involving central composite design (CCD) was employed for present experiment with application of Design Expert software 
(version 11.0.5.0). The design summary for N,O-carboxymethyl chitosan is given in Table-1 and as per design, 30 runs of experiment were carried out. Face centered design of CCD can be run sequentially, is very efficient and flexible [20]. The region of interest has been screened from the previous literature [5]. The Design Expert software was used to provide accurate regression analysis, input-output correlations, interaction amongst different screened parameters and optimization of process parameters [21,22].

\section{RESULTS AND DISCUSSION}

Characterization of N,O-carboxymethyl chitosan: N,Ocarboxymethyl chitosan powder was prepared in good yield from the reaction of chitosan and monochloroacetic acid as shown in Scheme-I.

Different N,O-carboxymethyl chitosan samples were produced by using different reaction times, different temperature and different ratio of chitosan/monochloroacetic acid. The formation of N,O-carboxymethyl chitosan was established by comparing FT-IR spectra (Fig. 1) of chitosan with that of synthesized CMCS6 (Table-2). Chitosan showed a broad band between 3500 and $3100 \mathrm{~cm}^{-1}$, which may be due to stretching O-H and $\mathrm{N}-\mathrm{H}$ bond. The bands observed at $1580 \mathrm{~cm}^{-1}$ was corresponded to the $\mathrm{N}-\mathrm{H}$ bending of primary amine. The band at $1660 \mathrm{~cm}^{-1}$

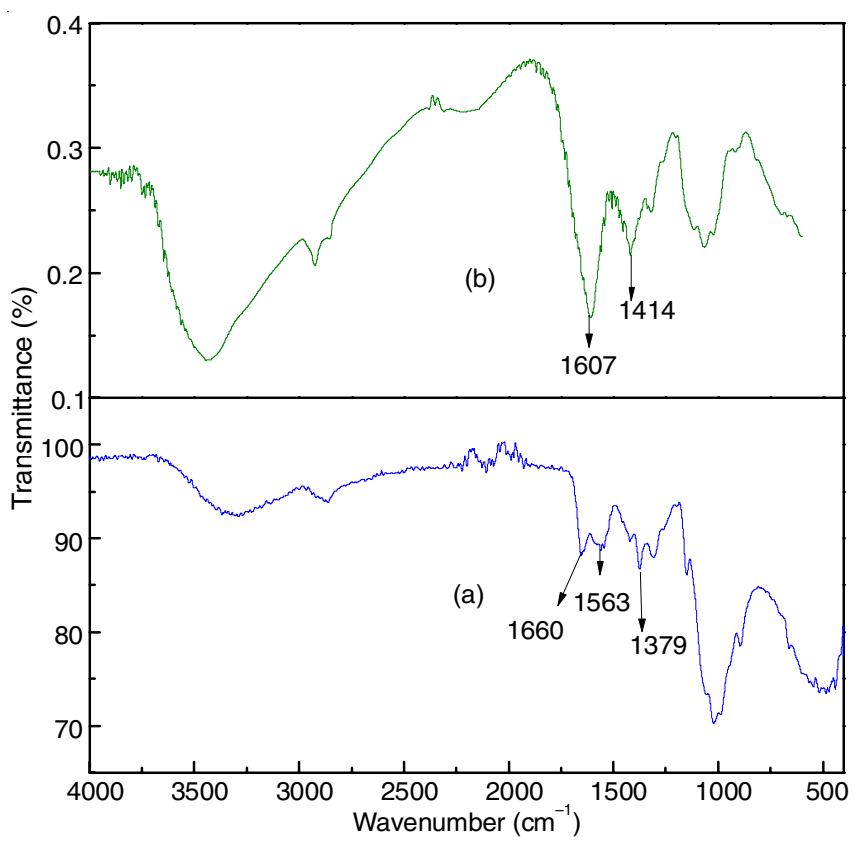

Fig. 1. FTIR spectra of (a) chitosan and (b) N,O-carboxymethyl chitosan
TABLE-2

DIFFERENT RESPONSE OF CHITOSAN AND CARBOXYMETHYL CHITOSAN

\begin{tabular}{cccc}
\hline Sample & Yield (\%) & $\begin{array}{c}\text { Degree of } \\
\text { acetylation }(\%)\end{array}$ & $\begin{array}{c}\text { Degree of } \\
\text { substitution }\end{array}$ \\
\hline Chitosan & - & 26.43 & - \\
CMCS $_{2}$ & 67.7 & 43.17 & 0.40 \\
$\mathrm{CMCS}_{6}$ & 78.2 & 33.99 & 0.56 \\
$\mathrm{CMCS}_{10}$ & 73.4 & 42.02 & 0.44 \\
\hline
\end{tabular}

is ascribed to the axial stretching of $\mathrm{C}=\mathrm{O}$ bond of acetamide groups, which gives the indication that sample is not fully deacetylated. A band at $1563 \mathrm{~cm}^{-1}$ is attributed to $\mathrm{N}-\mathrm{H}$ bending and the band $1379 \mathrm{~cm}^{-1}$ corresponding to C-N stretching of $\mathrm{N}$-acetyl group (Fig. 1a). On comparing the FTIR spectra of parent chitosan with N,O-carboxymethyl chitosan derivatives, additional peaks appeared which confirms the structural changes. The broadening of band at $3500-3100 \mathrm{~cm}^{-1}$ disclosed more hydrophilicity of N,O-carboxymethyl chitosan. The main characteristic band of carboxyl group $\mathrm{COOH}$ appeared at $1607 \mathrm{~cm}^{-1}$. The appearance of an intense band at $1607 \mathrm{~cm}^{-1}$ was ascribed to the symmetric COO- (which overlaps with $\mathrm{N}-\mathrm{H}$ bending) and another band at $1414 \mathrm{~cm}^{-1}$ corresponding to the asymmetric axial deformation of COO-, confirmed the formation of N,Ocarboxymethyl chitosan [23-27].

The ${ }^{1} \mathrm{H}$ NMR spectra was used to determine the structural modification of chitosan (Fig. 2a). The signal observed at 3.2 ppm attributed to the hydrogen bonded to $\mathrm{C}_{2}$ of glucosamine ring), peaks between 3.4 to $3.7 \mathrm{ppm}$ correspond to hydrogen atoms bonded to the carbon atoms $\mathrm{C}_{3}, \mathrm{C}_{4}, \mathrm{C}_{5}$ and $\mathrm{C}_{6}$ of glucopyranose ring. The signal at $4.6 \mathrm{ppm}$ corresponds to the hydrogen atom bonded to anomeric carbon $\mathrm{C}_{1}$ [28]. In case of N,O-carboxymethyl chitosan signals at $4.6 \mathrm{ppm}$ and $4.7 \mathrm{ppm}$ corresponding to the protons of $\mathrm{CH}_{2} \mathrm{COO}$ - at N-position on $\mathrm{C}_{2}$ and O-position on $\mathrm{C}_{6}$, respectively (Fig. 2b). Therefore, it can be concluded that modified chitosan contains carboxymethyl substitution on both amino $(-\mathrm{NH})$ and primary hydroxyl sites $(-\mathrm{OH})$ and hence confirmed the chemical modifications of chitosan successfully.

The X-ray diffraction (XRD) analysis also gives the clear idea of formation of N,O-carboxymethyl chitosan (Fig. 3). It is clear from Fig. 3 that carboxymethylation of chitosan has produced alteration in the array of chitosan chain. However, the spectrum of N,O-carboxymethyl chitosan is not well defined and much low intense peaks are observed in comparison to chitosan. The chitosan shows two different peak at $2 \theta=8.9^{\circ}$ and $20.10^{\circ}$ indicating that it is semi-crystalline in nature $[18$, 29,30]. Whereas, the XRD pattern for N,O-carboxymethyl-

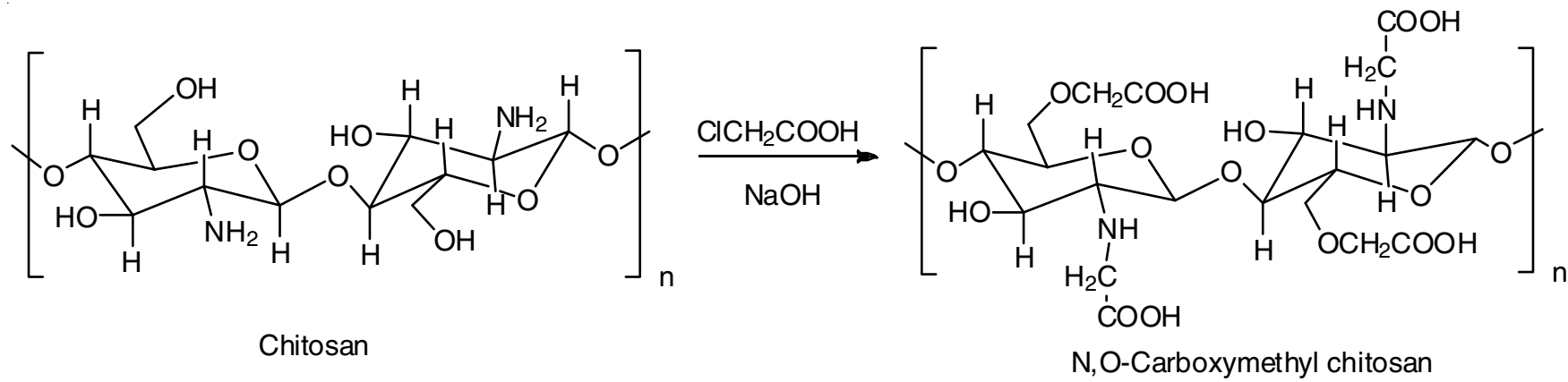

Scheme-I: Synthesis of N,O-carboxymethyl chitosan 


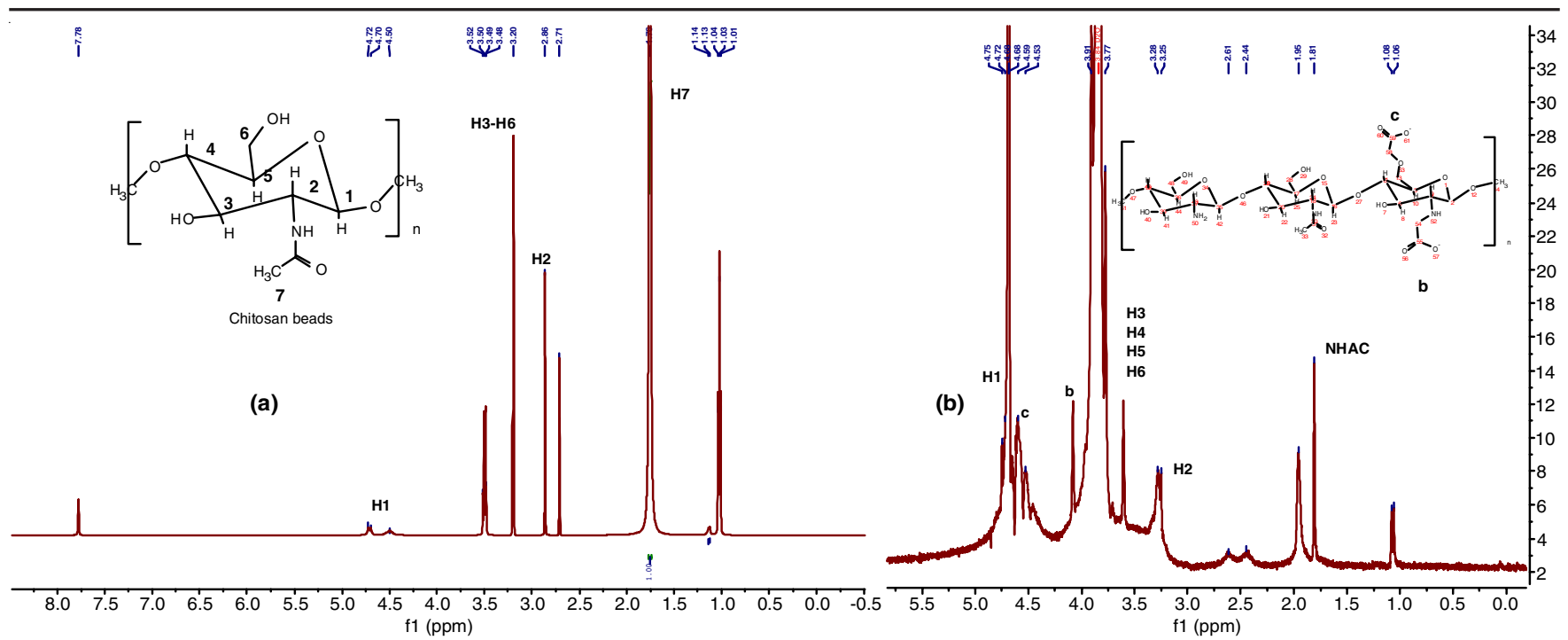

Fig. 2. ${ }^{1} \mathrm{H}$ NMR spectra of (a) chitosan and (b) N,O-carboxymethyl chitosan
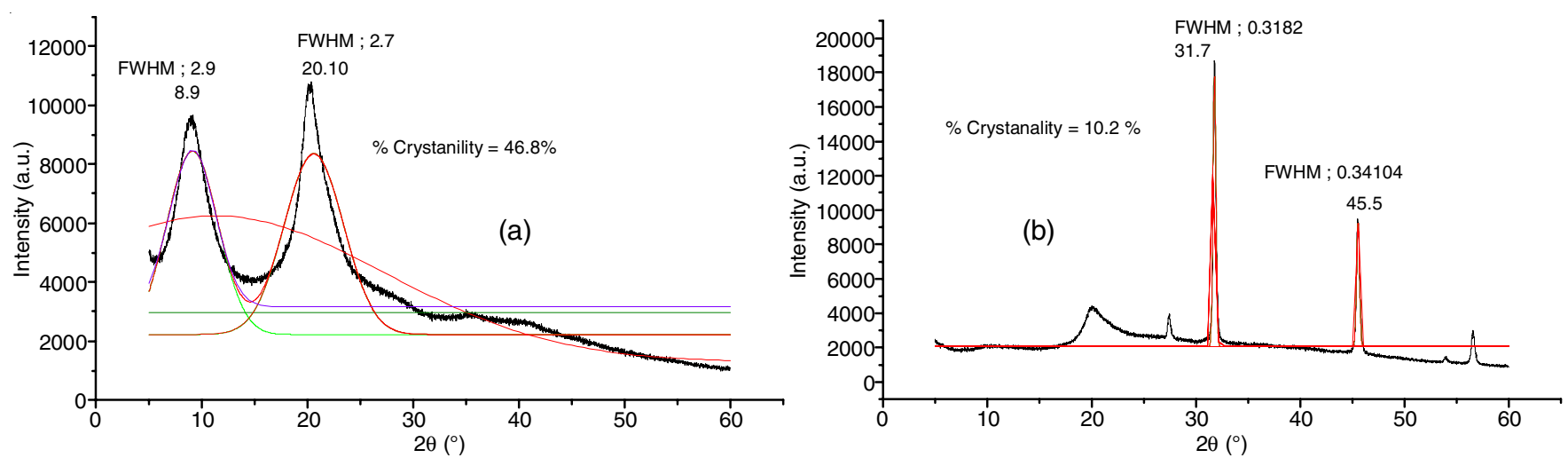

Fig. 3. XRD patterns of (a) chitosan and (b) N,O-carboxymethyl chitosan

chitosan does not contain the prominent peak at $8.9^{\circ}$ and the peak at $20.10^{\circ}$. These results confirms the amorphous nature of N,O-carboxymethyl chitosan. This is due to the destruction of intermolecular hydrogen bond between hydroxyl group and amine group of chitosan which was attributed to the increase in the substitution of chitosan. Therefore, crystallinity of N,Ocarboxymethyl chitosan decreased [31].

Thermal analysis: The thermogram of chitosan indicates mass loss in two steps (Fig. 4). In the first stage, mass loss of $14.82 \%$ up to $150^{\circ} \mathrm{C}$ was related to the loss of absorbed water and in the second stage mass loss of 56.068 \% up to 235-400 ${ }^{\circ} \mathrm{C}$ was due to the decomposition and depolymerization of acetylated and deacetylated chitosan unit. But in case of N,Ocarboxymethyl chitosan, in the first stage $11.6 \%$ mass loss between $20-200^{\circ} \mathrm{C}$ was assigned to the loss of water because polysaccharide has a strong affinity for water and thus easily hydrated. In the second stage, $35.87 \%$ mass loss between 200$500{ }^{\circ} \mathrm{C}$ was observed for the thermal decomposition of main chain of polysaccharide, vaporization and elimination of volatile products. The variation in thermogram for N,O-carboxymethylchitosan confirms the carboxymethylation of chitosan. The thermal stability of carboxymethyl chitosan is more in comparison to chitosan due to carboxymethyl group substitution.

SEM analysis: The scanning electron microscopy (SEM) of chitosan and N,O-carboxymethyl chitosan are shown in Fig. 5.

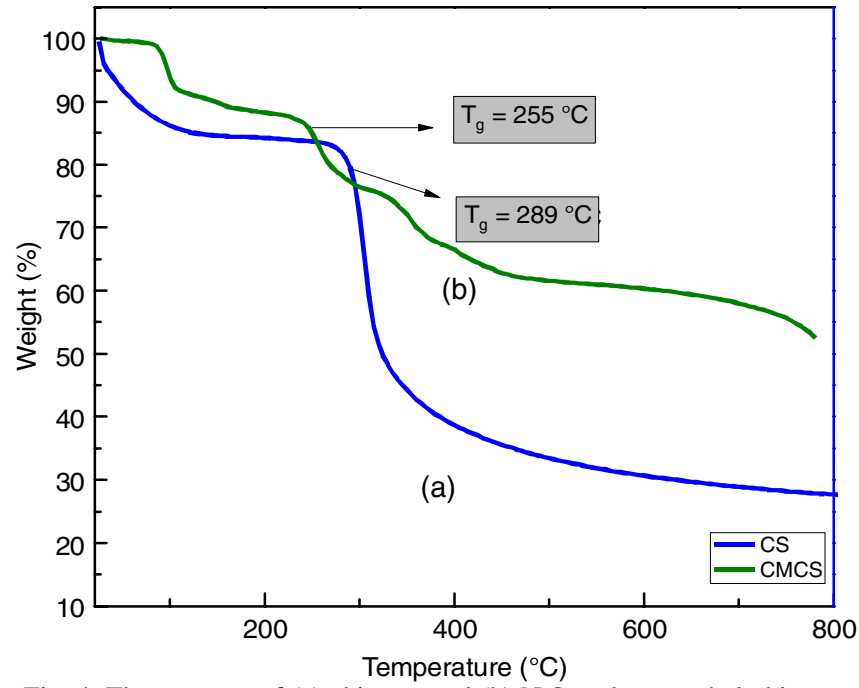

Fig. 4. Thermogram of (a) chitosan and (b) N,O-carboxymethyl-chitosan

Chitosan shows smooth, non-porous and flaky nature but after carboxymethylation process, the surface of chitosan has completely changed and lamellar and more lumps appeared on the surface of N,O-carboxymethyl chitosan which is attributed to the modification of chitosan surface by carboxymethyl groups. Overall N,O-carboxymethyl chitosan shows rough, lamellar and porous structure. These properties indicate that 


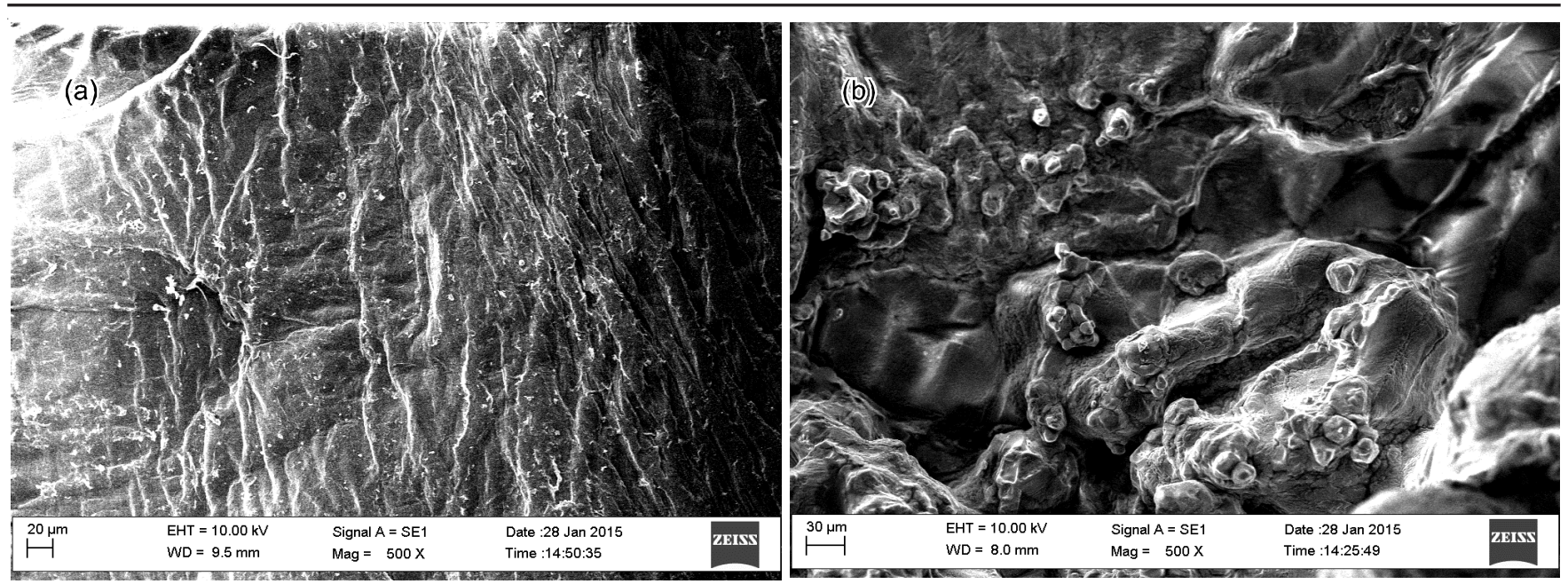

Fig. 5. SEM images of (a) chitosan and (b) N,O-carboxymethyl chitosan

the modified chitosan can hold drug particles in the pores present in them and also they may be more water soluble and swellable by absorbing water molecules.

By using viscometry, the average molecular weight of synthesized N,O-carboxymethyl chitosan were determined by using following equation:

$$
\eta=\mathrm{kM} \alpha
$$

where $\mathrm{M}$ is the average molecular weight; $\mathrm{k}$ and $\alpha$ are constants.

It was found that the molecular weight is in the order of $1.5 \times 10^{5}(\mathrm{~g} / \mathrm{mol})[18]$.

Determination of degree of acetylation (DA) and degree of substitution (DS) of chitosan and N,O-carboxymethylchitosan: The degree of acetylation (DA) and substitution (DS) of chitosan and carboxymethyl chitosan are very significant parameters that suggest the molar percentage of monomeric unit (amino group) [32]. Degree of acetylation (DA) can be related to biological, physico-chemical and mechanical properties such us solubility, reactivity and chain conformation. Thus, degree of acetylation (DA) is the most crucial parameter for the structure and properties of chitosan and its derivatives. Different N,O-carboxymethyl chitosan samples were synthe-

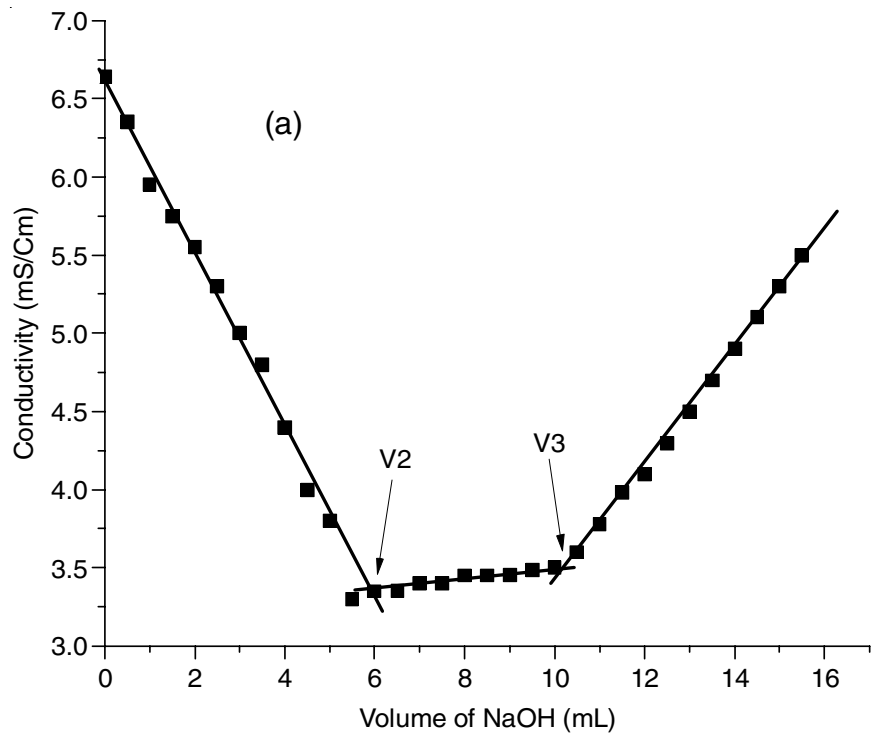

sized at different reaction times $(2,6$ and $10 \mathrm{~h})$ at $50^{\circ} \mathrm{C}$ and $1: 2$ ratio of chitosan/monochloroacetic acid resulting the samples CMCS2, CMCS6 and CMCS10, respectively (Table-2). The yield of N,O-carboxymethyl chitosan was calculated as follows:

$$
\text { Yield }(\%)=\left(\frac{\text { Weight of CMC }}{\text { Weight of chitosan }}\right) \times 100
$$

The degree of acetylation (DA) and substitution (DS) of chitosan and N,O-carboxymethyl chitosan were determined by conductometric titration curves. Carboxymethylation can be done in two different sites of chitosan such as - $\mathrm{OH}$ group linked with $\mathrm{C}_{3}$ and $\mathrm{C}_{6}$ of glucopyranose and $-\mathrm{NH}_{2}$ group attached with $\mathrm{C}_{2}$ [33]. The conductometric curve of carboxymethyl chitosan $\mathrm{CMCS}_{6}$ is different than chitosan (Fig. 6). In the present study, for $\mathrm{CMCS}_{6}$ four linear branches were observed. The first linear curve corresponding to the amount of base used for the neutral-ization of the excess of $\mathrm{HCl}$ i.e. 0 to $\mathrm{V}_{1}$. The second equivalence point showed that $\mathrm{NaOH}$ reacted with carboxymethyl chitosan from $\mathrm{V}_{1}$ to $\mathrm{V}_{2}$ and their difference $\left(\mathrm{V}_{2}-\mathrm{V}_{1}\right)$ indicated that $\mathrm{NaOH}$ is necessary to neutralize $-\mathrm{CH}_{2} \mathrm{COOH}$ group. The third equivalence point $\left(\mathrm{V}_{3}\right)$ and the

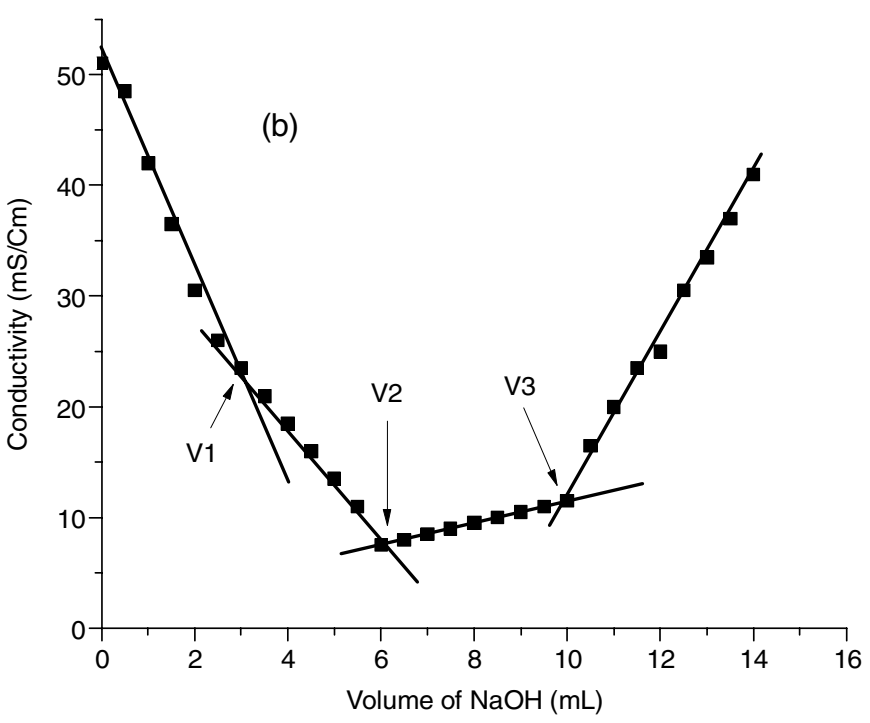

Fig. 6. Conductometric titration curve of (a) chitosan and (b) $\mathrm{CMCS}_{6}$ 
difference $\left(\mathrm{V}_{3}-\mathrm{V}_{2}\right)$ showed the volume of $\mathrm{NaOH}$ reacted with $\mathrm{NH}_{3}{ }^{+}$groups. The fourth linear branch of curve showed that the excess amount of $\mathrm{NaOH}$. From the conductometric titration curves, degree of acetylation and degree of substitution can be calculated (Table-2). The higher degree of acetylation of $\mathrm{N}, \mathrm{O}$-carboxymethyl chitosan than chitosan indicates that that $\left(-\mathrm{NH}_{2}\right)$ groups were also carboxy-methylated (Table-2) [34-36].

The values of degree of substitution (DS) of samples $\mathrm{CMCS}_{2}$, $\mathrm{CMCS}_{6}$ and $\mathrm{CMCS}_{10}$ (Table-2) are almost same, which may be due to insignificant effect of reaction time (Fig. 9). With prolonged time period the concentration of monochloroacetic acid reduces as it preferentially react with sodium hydroxide.

Experimental design on degree of substitution: Analysis of results obtained by design expert software shows the significant effects of various parameters on analysis of degree of substitution [37].

Effect of amount of chitosan on degree of substitution: Higher the amount of chitosan, the higher will be the degree of acetylation (DA) (Fig. 7). The maximum degree of acetylation obtained is 0.56 at $1.25 \mathrm{~g}$ of chitosan. However with further increase in chitosan amount, degree of substitution decreases as the saturation approaches with respect to monochloroacetic acid and $\mathrm{NaOH}$ amount.

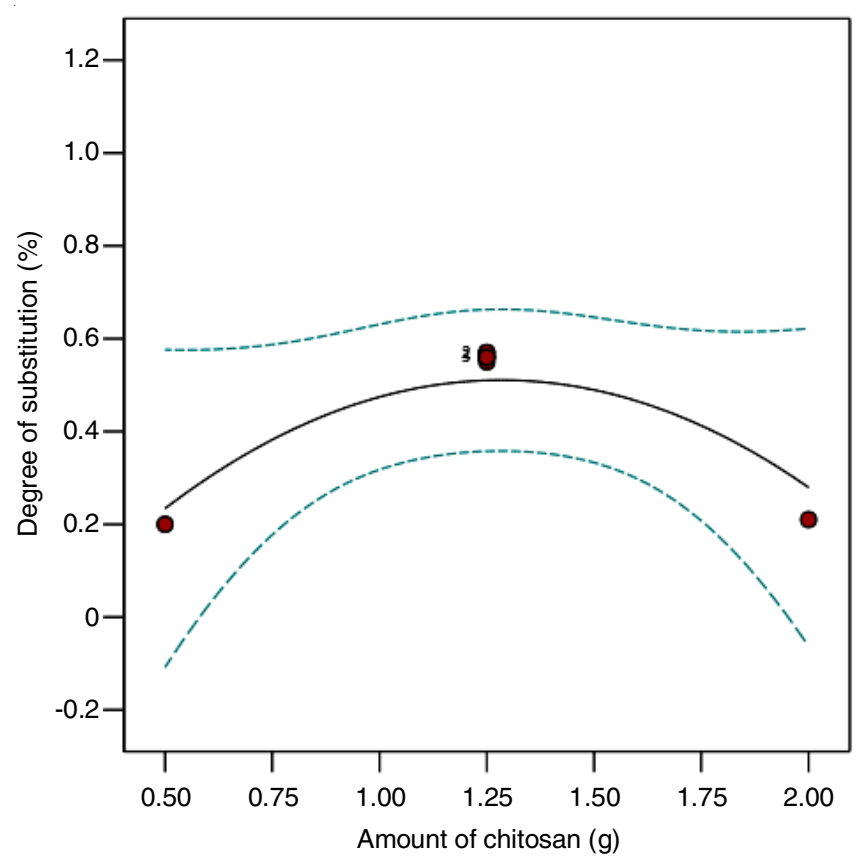

Fig. 7. Effect of amount of chitosan on degree of substitution

Effect of amount of monochloroacetic acid on degree of substitution (DS): The amount of monochloroacetic acid plays a significant role in determining the production of carboxymethyl chitosan. An increase in monochloroacetic acid amount, degree of substitution (DS) increases rapidly and approaches a maximum value of 0.56 and the decreases with further increase in monochloroacetic acid amount (Fig. 8). This may be due to at high concentration of monochloroacetic acid as all the $\mathrm{NaOH}$ are consumed.

Effect of reaction time on degree of substitution: The effect of reaction time on degree of substitution increases rapidly with increase in time until the maximum value of degree of

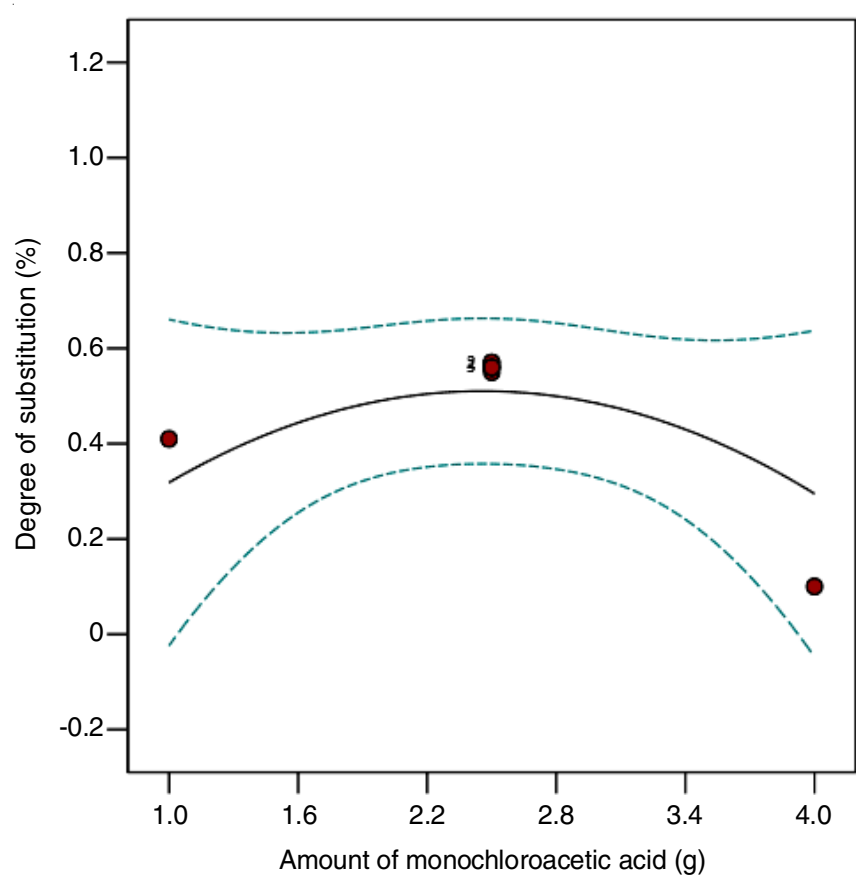

Fig. 8. Effect of amount of monochloroacetic acid on degree of substitution

substitution of 0.56 was achieved at 6 h (Fig. 9). On further increase in reaction time, the degree of substitution decreases. This may be due to with longer prolongation period of carboxymethylation which may resulted the atmospheric degradation of carboxymethyl chitosan.

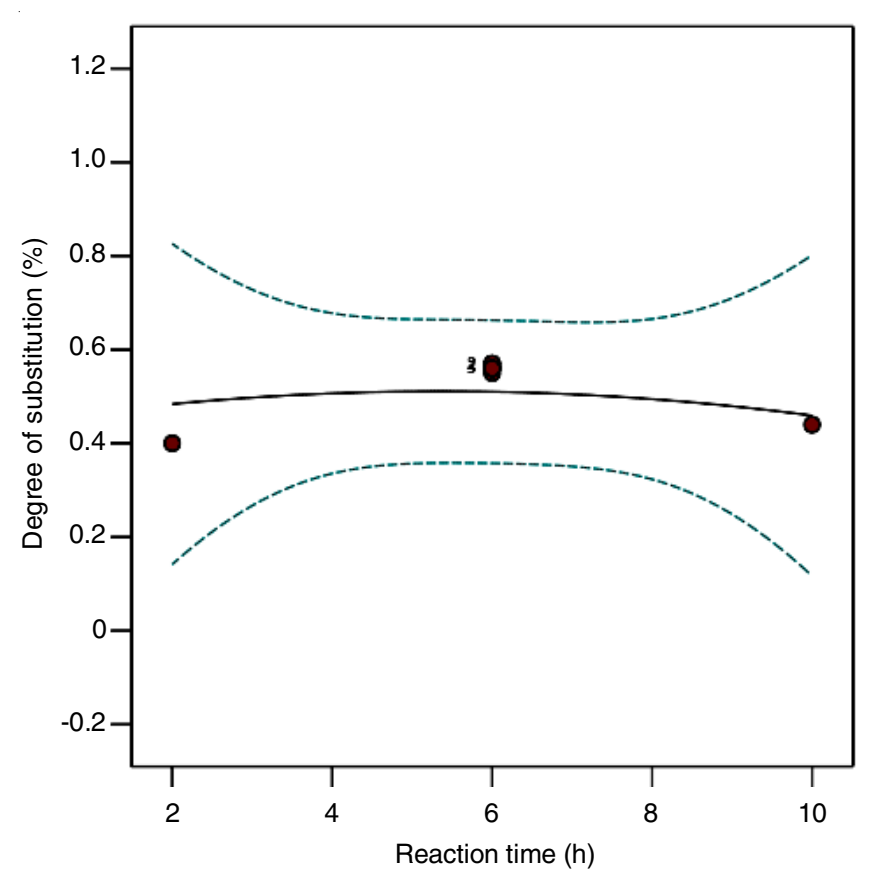

Fig. 9. Effect of reaction time on degree of substitution

Effect of reaction temperature on degree of substitution: The effect of reaction temperature on degree of substitution shows an increasing trend. From Fig. 10, it is clear that the value of degree of substitution is found to be 1.13 at $70{ }^{\circ} \mathrm{C}$. This increase trend observed may be due to the alkalization process at higher temperature, which increases the value of degree of substitution [2]. 


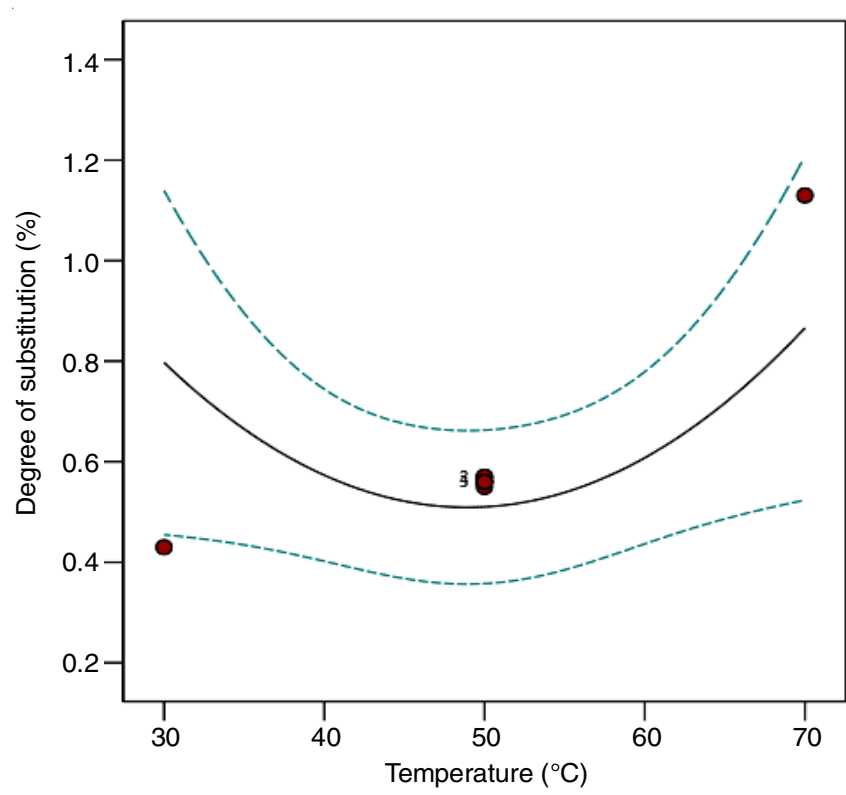

Fig. 10. Effect of reaction temperature on degree of substitution

Optimization using response surface methodology: The optimization conditions for obtaining the maximum degree of substitution are given in Table-3.

\begin{tabular}{cc} 
TABLE 3 \\
OPTIMIZED CONDITIONS FOR DEGREE OF SUBSTITUTION \\
\hline Conditions & Values \\
\hline Reaction temperature $\left({ }^{\circ} \mathrm{C}\right)$ & 50 \\
Reaction time $(\mathrm{h})$ & 6 \\
Monochoroacetic acid $(\mathrm{g})$ & 2.5 \\
Chitosan $(\mathrm{g})$ & 1.25 \\
\hline
\end{tabular}

\section{Conclusion}

Chitosan was successfully converted to N,O-carboxymethyl chitosan and its structure was confirmed by NMR and FT-IR. Thermal stability and the percentage of crystallinity of CMCS determined by TGA and XRD, respectively which are well agreed with the modification of chitosan. The XRD analysis showed that chitosan is more crystalline than N,O-carboxymethyl chitosan. The morphology of carboxymethyl chitosan studied by SEM technique also proves the same. The optimization condition for degree of acetylation, degree of substitution and yield were obtained by using RSM.

\section{ACKNOWLEDGEMENTS}

The authors are thankful to National Institute of Technology, Raipur and Ravenshaw University, Cuttack, India for providing the necessary research facilities.

\section{CONFLICT OF INTEREST}

The authors declare that there is no conflict of interests regarding the publication of this article.

\section{REFERENCES}

1. M.R. Saboktakin, R.M. Tabatabaie, A. Maharramov and M.A. Ramazanov, Carbohydr. Polym., 81, 726 (2010);

https://doi.org/10.1016/j.carbpol.2010.03.047.
2. J. Wang, J.-S. Chen, J.-Y. Zong, D. Zhao, F. Li, R.-X. Zhuo and S.-X. Cheng, J. Phys. Chem. C, 114, 18940 (2010); https://doi.org/10.1021/jp105906p.

3. B. Shi, Z. Shen, H. Zhang, J. Bi and S. Dai, Biomacromolecules, 13, 146 (2012); https://doi.org/10.1021/bm201380e.

4. M. Periayah, A.S. Halim, S. Gomathysankar, A.A. Ahmad Sukari,, A.Z. Mat Saad, A.H. Abdul Rashid, Z. Ujang and N.Z. Mohd Muslim, Int. J. Basic Appl. Sci., 3, 532 (2014);

https://doi.org/10.14419/ijbas.v3i4.3548.

5. M. Rinaudo, Prog. Polym. Sci., 31, 603 (2006); https://doi.org/10.1016/j.progpolymsci.2006.06.001.

6. A. Teotia, S. Ikram and B. Gupta, Polym. Bull., 69, 175 (2012); https://doi.org/10.1007/s00289-010-0415-6.

7. N.A. Mohamed and N.A.A. El-Ghany, Int. J. Bio. Macromol., 50, 1280 (2012);

https://doi.org/10.1016/j.ijbiomac.2012.03.011.

8. T.-Y. Liu, S.-Y. Chen, Y.-L. Lin and D.-M. Liu, Langmuir, 22, 9740 (2006); https://doi.org/10.1021/la061471n.

9. J. Jin, Z. Ji, M. Xu, C. Liu, X. Ye, W. Zhang, S. Li, D. Wang, W. Zhang, J. Chen, F. Ye and Z. Lv, ACS Biomater. Sci. Eng., 4, 2541 (2018); https://doi.org/10.1021/acsbiomaterials.8b00453.

10. W. Dong, B. Han, Y. Feng, F. Song, J. Chang, H. Jiang, Y. Tang and W. Liu, Biomacromolecules, 11, 1527 (2010); https://doi.org/10.1021/bm100158p.

11. S. Mantri, A. Routaray, N. Nath, A.K. Sutar and T. Maharana, Polym. Int., 66, 313 (2017); https://doi.org/10.1002/pi.5268

12. A. Routaray, S. Mantri, N. Nath, A.K. Sutar and T. Maharana, Polyhedron, 119, 335 (2016); https://doi.org/10.1016/j.poly.2016.08.032.

13. S. Vaghani, S. Vasanti, K. Chaturvedi, C.S. Satish and N.P. Jivani, Pharm. Dev. Technol., 15, 154 (2010); https://doi.org/10.3109/10837450903085392.

14. G.A.F. Roberts and J.G. Domszy, Int. J. Biol. Macromol., 4, 374 (1982); https://doi.org/10.1016/0141-8130(82)90074-5.

15. M. Rinaudo, M. Milas and P.L. Dung, Int. J. Biol. Macromol., 15, 281 (1993); https://doi.org/10.1016/0141-8130(93)90027-J.

16. A. Zamani, D. Henriksson and M.J. Taherzadeh, Carbohydr Polym., 80, $1091(2010)$ https://doi.org/10.1016/j.carbpol.2010.01.029.

17. H.C. Ge and D.K. Luo, Carbohydr. Res., 340, 1351 (2005); https://doi.org/10.1016/j.carres.2005.02.025.

18. E.M. El-Nesr, A.I. Raafat, S.M. Nasef, E.A. Soliman and El-Sayed A. Hegazy, Arab. J. Nucl. Sci. Appl., 47, 14 (2014).

19. T.D. Farahani, E.V. Farahani and H. Mirzadeh, Iran. Polym. J., 15, 405 (2006).

20. T. Maharana, Ph.D. Thesis, Synthesis and Characterizations of Poly(lactic acid) and its Nanoparticles, Indian Institute of Technology Roorkee, Roorkee, India (2010).

21. T. Maharana, B. Mohanty and Y.S. Negi, Int. J. Green Nanotechnol.: Phys. Chem., 2, 100 (2010); https://doi.org/10.1080/19430876.2010.532462.

22. C.J. Tijsen, H.J. Scherpenkate, E.J. Stamhuis and A.A.C.M. Beenackers, Chem. Eng. Sci., 54, 2765 (1999); https://doi.org/10.1016/S0009-2509(98)00321-2.

23. S.S. Vaghani, M.M. Patel, C.S. Satish, K.M. Patel and N.P. Jivani, Bull. Mater. Sci., 35, 1133 (2012).

24. S. Yu, J. Du, Y. Zheng and L. Yan, J. Appl. Polym. Sci., 106, 4098 (2007); https://doi.org/10.1002/app.26947.

25. J. Liu, J.-F. Lu, J. Kan, Y.-Q. Tang and C.-H. Jin, Int. J. Biol. Macromol., 62, 85 (2013); https://doi.org/10.1016/j.ijbiomac.2013.08.040.

26. F.R. de Abreu and S.P. Campana-Filho, Carbohyd. Polym., 75, 214 (2009); https://doi.org/10.1016/j.carbpol.2008.06.009.

27. V.K. Mourya, N.N. Inamdara and Ashutosh Tiwari, Adv. Mater. Lett., 1, 11 (2010); https://doi.org/10.5185/amlett.2010.3108

28. Y.-C. Huang and T.-H. Kuo, Food Hydrocoll., 53, 261 (2016); https://doi.org/10.1016/j.foodhyd.2015.02.006. 
29. J.M. Joshi and V.K. Sinha, Polym. Res., 13, 387 (2006); https://doi.org/10.1007/s10965-006-9056-8.

30. T. Baran, A. Mentes and H. Arslan, Int. J. Biol. Macromol., 72, 94 (2015); https://doi.org/10.1016/j.ijbiomac.2014.07.029.

31. P. Katugampola, C. Winstead and A. Adeleke, Int. J. Pharm. Sci. Invent., 3, 42 (2014).

32. C. Sun, J.S. Lee and M. Zhang, Adv, Drug Deliv. Rev., 60, 1252 (2008); https://doi.org/10.1016/j.addr.2008.03.018.

33. S.C. Chen, Y.C. Wu, F.L. Mi, Y.H. Lin, L.C. Yu and H.W. Sung, J. Control. Rel., 96, 285 (2004);

https://doi.org/10.1016/j.jconrel.2004.02.002.
34. A. Casaburi, U.M. Rojo, P. Cerrutti, A. Vazquez and M.L. Foresti, Food Hydrocoll., 75, 147 (2018); https://doi.org/10.1016/j.foodhyd.2017.09.002.

35. Z. Li, Y. Wang, Y. Pei, W. Xiong, W. Xu, B. Li and J. Li, Food Hydrocoll., 62, 222 (2017);

https://doi.org/10.1016/j.foodhyd.2016.07.020.

36. L. Peirez-Ailvarez, L. Ruiz-Rubio and J.L. Vilas-Vilela, J. Chem. Educ., 95, 1022 (2018); https://doi.org/10.1021/acs.jchemed.7b00902.

37. D. Bas and I.H. Boyac, J. Food Eng., 78, 836 (2007); https://doi.org/10.1016/j.jfoodeng.2005.11.024. 